\title{
BAHAN AJAR
}

\section{ADMINISTRASI PENDIDIKAN}

( Bahan Ajar Semester V )

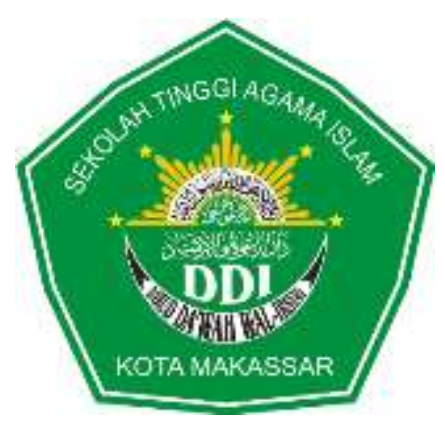

Disusun Oleh

Muhammad Arsyam, S.PDI., M.Pd

SEKOLAH TINGGI AGAMA ISLAM

DARUD DA'WAH WAL-IRSYAD (STAI-DDI)

KOTA MAKASSAR

TAHUN 2020/2021 


\section{ADMINISTRASI PENDIDIKAN \\ Muhammad Arsyam, S.PDI., M.Pd \\ arsyam0505@gmail.com}

\section{A. Pengertian Administrasi}

Apa yang dimaksud dengan administrasi? Pengertian Administrasi adalah sebuah bentuk usaha dan aktivitas yang berhubungan dengan pengaturan kebijakan agar dapat mencapai target/ tujuan organisasi. Jadi, boleh dibilang bahwa administrasi punya peranan yang sangat krusial dalam semua aktivitas sebuah organisasi.

Selain itu, pengertian administrasi secara sempit dapat diartikan sebagai bentuk aktivitas yang meliputi catat-mencatat, surat-menyurat, pembukuan sederhana, ketikmengetik, dan kegiatan lain yang sifatnya teknis ketatausahaan. Sedangkan pengertian

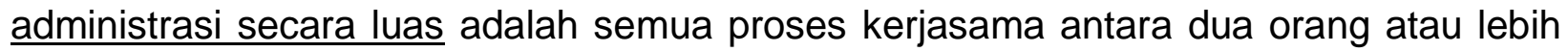
yang bertujuan untuk mencapai target dengan memanfaatkan sarana dan prasarana tertentu secara berdaya guna dan berhasil guna.

Dari definisi administrasi tersebut kita dapat mengetahui 3 hal penting berikut ini:

- Administrasi adalah sebuah seni sekaligus proses. Sebagai seni, administrasi membutuhkan kiat khusus yang sifatnya kondisional dan situasional karena selalu terkait dengan situasi, kondisi, waktu, dan tempat.

- Dalam administrasi terdapat unsur-unsur tertentu, diantaranya; terdapat dua atau lebih orang di dalamnya, terjadi kerjasama antar orang tersebut yang sifatnya formal dan hirarkis, memiliki tujuan, terdapat tugas, ketersediaan sarana dan prasarana.

- Administrasi muncul secara bersamaan dengan munculnya peradaban manusia dimana administrasi tersebut untuk mencapai tujuan bersama. 
Pengertian Administrasi Menurut Para Ahli beberapa ahli di bidang administrasi menjelaskan tentang definisi administrasi, diantaranya adalah:

1. George R. Terry

Menurut George R. Terry, pengertian administrasi adalah kegiatan perencanaan, pengendalian, dan pengorganisasian pekerjaan perkantoran, serta penggerakan mereka yang melaksanakannya agar mencapai tujuan yang telah ditetapkan.

2. Arthur Grager

Menurut Arthur Grager, pengertian administrasi adalah fungsi tata penyelenggaraan terhadap komunikasi dan pelayanan warkat suatu organisasi.

3. Sondang P. Siagian

Menurut Sondang P. Siagian, arti administrasi adalah segala bentuk dari proses kerjasama antara dua individu atau lebih atas dasar rasionalitas terpilih untuk mencapai tujuan yang ditentukan sebelumnya.

4. Ulbert

Menurut Ulbert, dalam artian luas arti administrasi adalah penyusunan dan pencatatan data/ informasi secara sistematis, baik internal maupun eksternal sebagai upaya untuk menyediakan keterangan serta memudahkan untuk mendapatkannya kembali, baik itu sebagian ataupun seluruhnya. Sedangkan defenisi administrasi dalam arti sempit dikenal dengan istilah tata usaha.

5. Willam Lefffingwell dan Edwin Robinson

Menurut Willam Lefffingwell dan Edwin Robinson, pengertian administrasi adalah suatu bagian dari ilmu manajemen yang berkaitan dengan pelaksanaan pekerjaan perkantoran secara efisien, kapan dan di mana pekerjaan tersebut harus dilakukan.

Baca juga: Pengertian Manajemen Administrasi 


\section{B. Unsur-Unsur Administrasi}

Selain memahami pengertian administrasi, ada beberapa unsur penting yang wajib ada di sebuah bidang bisnis. Menurut The Liang Gie, ada 8 unsur yang harus ada:

\section{Organisasi}

Tempat dimana kegiatan administrasi dilakukan. Dalam bisnis, orang-orang yang bekerja di dalamnya akan dihimpun mejadi sebuah wadah.

\section{Manajemen}

Alat utama pelaksanaan administrasi. Ada pengatur, penggerak, manajer dan tenaga operasional. Dalam manajemen ini masih dibagi menjadi tiga kelompok; top management, middle management dan lower management (mandor).

3. Komunikasi

Administrasi juga mengatur pola komunikasi antar departemen. Misalnya melalui surat atau warta.

\section{Kepegawaian}

Ini berkaitan dengan penggunaan ternaga kerja. Dalam administrasi ada proses yang saling berhubungan, yaitu; penerimaan, penempatan, pendayagunaan dan pemberhentian kerja.

5. Keuangan

Ini berkaitan dengan pembiayaan kontrak kerjasama mulai dari cara memperoleh dana hingga pertanggungjawabannya.

\section{Perbekalan}

Berhubungan dengan pengadaan barang, penyimpanan dan penyingkiran. Pihak administrasi akan menyisir mana barang yang dibutuhkan untuk kerja dan tidak. 
7. Tata usaha

Meliputi kegiatan pencatatan, penyimpanan dan pengiriman.

8. Public Relation

Administrasi akan menciptakan peraturan bagaimana berhubungan dengan masyarakat terutama konsumen.

\section{Ciri-Ciri Administrasi}

Administrasi memiliki beberapa karakteristik/ciri-ciri antara lain sebagai berikut:

1. Di dalam kegiatan Administrasi ada beberapa karakteristik/ ciri-ciri yang mudah dikenali, diantaranya adalah:

2. Administrasi memiliki tujuan yang jelas

3. Di dalam Administrasi terdapat kelompok manusia yang terdiri dari dua orang atau lebih

4. Administrasi selalu berhubungan dengan kegiatan kerjasama

5. Di dalam Administrasi terdapat usaha atau proses kerja

6. Kegiatan di dalam Administrasi selalu terdapat kepemimpinan, bimbingan, dan pengawasan

\section{Fungsi Administrasi}

Berikut ini adalah beberapa fungsi administrasi dalam organisasi:

1. Planning (Perencanaan)

Planning adalah kegiatan perencana yang membutuhkan sebuah aktivitas administrasi, mulai dari pengumpulan data, pengolahan data, hingga penyusunan perencanaan. 


\section{Organizing (Penyusunan)}

Organizing adalah kegiatan menyusun dan membangun komunikasi kerja antara anggota-anggota dalam organisasi sehingga akan tercapai suatu kesatuan usaha untuk mencapai tujuan organisasi tersebut

3. Coordinating (Kordinasi)

Coordinating merupakan sebagian dari fungsi manajemen yang melakukan sejumlah aktivitas agar berjalan baik dengan menjauhi terjadinya suatu kekacauan, bentrok, kekosongan aktivitas yang dilaksanakan dengan menghubungkan, menyatukan dan menyesuaikan suatu pekerjaan bawahan yang sehingga terdapat kerjasama yang terencana dalam suatu usaha untuk mencapai suatu tujuan organisasi.

\section{Reporting (Laporan)}

Reporting adalah aktivitas penyampaian perkembangan atau hasil dari suatu kegiatan dengan membuat dan memberikan laporan dari tugas dan fungsi para pejabat yang lebih tinggi baik lisan ataupun tulisan untuk mendapatkan gambaran tentang pelakasanaan tugas para anggota organisasi.

5. Budgeting (Penyusunan Anggaran)

Budgeting adalah aktivitas perencanaan dan pengelolaan keuangan atau anggaran dalam organisasi yang dilakukan secara berkesinambungan.

6. Staffing (Penempatan)

Staffing adalah kegiatan yang berhubuungan dengan sumber daya manusia dan sumber daya lainnya dalam sebuah organisasi; mulai dari perkrutan tenaga kerja, pengembangan, perlengkapan di dalam organisasi tersebut. 


\section{Directing (Pengarahan atau Bimbingan)}

Directing adalah aktivitas berinteraksi dengan anggota organisasi dalam bentuk memberi bimbingan, saran, perintah-perintah, agar tugas dijalankan dengan baik guna mencapai tujuan yang telah ditentukan.

Karena itu, bidang ini setidaknya harus bisa meng-cover beberapa hal berikut ini:

- Memahami pengertian administrasi

- Meningkatkan kinerja staf kantor dalam hal pengorganisasian dan mengatur administrasi kantor di berbagai bidang

- Mengeluarkan standar filing yang tepat

- Mengembangkan dan mengatur aset perusahaan

- Mampu mengembangkan prosedur administrasi

- Mampu mengontrol dan merencanakan budget administrasi

- Membuat laporan kegiatan perusahaan mulai dari penggajian, kegiatan pengiriman dan lainnya

Walaupun begitu, tugas utama administrator tergantung perusahaan. Yang pasti bidang ini akan memastikan efisiensi performa perusahaan di semua departemen. Mereka bertindak sebagai jembatan penghubung antara manejemen dan juga karyawan. Adminisrasi kantor adalah salah satu elemen yang dikaitkan dengan efisiensi dan produktifitas kerja perusahaan. Mereka memberikan informasi yang dibutuhkan oleh berbagai departemen sehingga masing-masing job description dan planning setiap menejemen tercapai.

Mereka menyediakan apa yang dibutuhkan oleh berbagai departemen, membangun peraturan dan budaya perusahaan. Kelihatannya, bidang ini seperti hilang ditelan bumi, padahal administrasi adalah kunci utama kelancaran regulasi perusahaan. 


\section{E. Pengertian Administrasi Pendidikan}

Apa yang dimaksud dengan administrasi pendidikan? Pengertian Administrasi Pendidikan adalah proses atau upaya pencapaian suatu tujuan pendidikan dengan memperhatikan berbagai komponen pendidikan sehingga dapat melakukan perbaikan sistem pendidikan dengan memanfaatkan berbagai perangkat pendukung aktivitas belajar dan mengajar.

Ada banyak upaya yang bisa dilakukan untuk mencapai tujuan manajemen pendidikan tersebut. Misalnya, memastikan masyarakat mendapatkan pendidikan wajib belajar 9 tahun, melanjutkan ke sekolah menengah atas, bahkan perguruan tinggi bila memungkinkan.

Di dalam berbagai makalah disebutkan bahwa pendidikan bukan hanya dalam bidang akademis saja, tapi juga mencakup pendidikan lainnya. Misalnya pendidikan karakter yang didapatkan dari keluarga, pendidikan keahlian, pendidikan tata krama, dan lain-lain.

Singkatnya, administrasi pendidikan adalah keseluruhan proses dan kegiatankegiatan bersama yang harus dilakukan oleh semua pihak yang ada kaitannya dengan tugas-tugas pendidikan.

Pengertian Administrasi Pendidikan Menurut Para Ahli Agar lebih memahami apa arti administrasi pendidikan, maka kita dapat merujuk pada pendapat beberapa ahli berikut ini:

\section{Drs. M. Ngalim Purwanto}

Menurut Drs. M. Ngalim Purwanto, pengertian Administrasi Pendidikan adalah seluruh proses pengarahan dan integrasi segala sesuatu baik personal, spiritual, dan material yang berkaitan dengan tercapainya tujuan pendidikan. 


\section{Depdiknas RI}

Menurut Depdiknas RI, Administrasi pendidikan adalah suatu keseluruhan proses kegiatan bersama dalam bidang pendidikan yang meliputi perencanaan, pengorganisasian, pengarahan, pengkoordinasian, pengawasan, pembiyaan, dan pelaporan, dengan memanfaatkan fasilitas yang tersedia, baik personal, material, dan spiritual demi tercapainya tujuan pendidikan secara efektif dan efisien.

3. Dasuqi dan Somantri

Menurut Dasuqi dan Somantri, definisi administrasi pendidikan adalah upaya menerapkan kaidah-kaidah administrasi dalam bidang pendidikan.

\section{Hadari Nawawi}

Menurut Hadari Nawawi, pengertian administrasi pendidikan adalah rangkaian kegiatan atau keseluruhan proses pengendalian usaha kerjasama sejumlah orang untuk mencapai tujuan pendidikan secara sistematis yang diselenggarakan dalam lingkungan tertentu, terutama dalam lembaga pendidikan formal.

\section{Oteng Sutisna}

Menurut Oteng Sutisna, pengertian administrasi pendidikan adalah suatu upaya mengkoordinasikan kegiatan yang saling bergantung dari orang-orang dan kelompokkelompok dalam mencapai tujuan bersama pendidikan anak-anak.

\section{F. Tujuan Administrasi Pendidikan}

Secara garis besar, tujuan administrasi pendidikan adalah untuk mencapai tujuan dari pendidikan itu sendiri atau sebagai alat untuk mencapai tujuan pendidikan. Menurut Sergiovanny dan Carver, ada 4 tujuan administrasi, yaitu:

1. Efektivitas produksi 


\section{Efisiensi}

3. Kemampuan menyesuaikan diri

4. Kepuasan Kerja

Nah bila dihubungkan dengan pengertiannya di atas, maka dapat disimpulkan bahwa tujuan administrasi ini adalah agar semua upaya dalam memanfaatkan berbagai sumber daya dapat dilaksanakan dengan efektif dan efisien dalam pencapaian tujuan pendidikan.

Dalam konteks pendidikan di Indonesia, administrasi pendidikan adalah subsistem dari sistem pendidikan nasional. Dengan begitu maka tujuannya adalah mendukung tercapainya tujuan pendidikan nasional.

Seperti yang disebutkan pada Pembukaan Undang-Undang Dasar 1945, tujuan pendidikan Negara Republik Indonesia adalah untuk mencerdaskan kehidupan bangsa. Hal tersebut dijabarkan kembali dalam Undang-Undang No. 20 Tahun 2003 tentang Sistem Pendidikan Nasional yang menyebutkan bahwa tujuan pendidikan nasional adalah mendidik dan mengembangkan peserta didik agar menjadi manusia yang beriman dan bertakwa kepada Tuhan yang Maha Esa, berakhlak mulia, sehat, berilmu, cakap, kratif, mandiri, dan bertanggungjawab.

\section{G. Fungsi Administrasi Pendidikan}

Secara umum ada 8 fungsi administrasi pendidikan, diantaranya adalah:

\section{Perencanaan (Planning)}

Isi dari perencanaan dalam administrasi pendidikan mencakup apa saja yang akan dilakukan, dan bagaimana cara melakukannya. 


\section{Pengorganisasian (Organizing)}

Pengorganisasian adalah kegiatan penyusunan dan pembentukan hubungan kerja antar individu. Dengan begitu, kesatuan usaha dalam upaya pencapaian maksud dan tujuan administrasi pendidikan dapat terwujud.

3. Kordinasi (Coordinating)

Kordinasi merupakan upaya yang dilakukan untuk menghindari terjadinya kesimpangsiuran dalam bertindak. Dengan kata lain, kordinasi adalah kegiatan yang membawa manusia, material, ide, teknik, dan tujuan ke dalam suatu hubungan yang harmonis serta produktif.

4. Komunikasi (Comunicating)

Komunikasi merupakan hal yang sangat penting dalam pelaksanaan suatu program pendidikan. Aktivitas komunikasi (baca: pengertian komunikasi) ini mencakup penyebaran dan penyampaian gagasan dan maksud, baik secara tertulis maupun lisan. 5. Pengawasan (Supervision)

Dalam pelaksanaan program pendidikan tentu harus disertai dengan adanya pengawasan. Proses pengawasan program pendidikan harus dilakukan dengan teliti agar tujuan pendidikan dapat tercapai.

6. Kepegawaian (Staffing)

Fungsi kepegawaian sudah berjalan mulai dari proses perencanaan dan pengorganisasian. Dalam hal ini, administrasi pendidikan mengupayakan agar yang dipilih untuk menduduki jabatan tertentu adalah orang-orang yang punya kemampuan dan kapabilitas sesuai dengan jabatan yang diberikan. 


\section{Penganggaran (Budgeting)}

Budgeting adalah anggaran biaya yang direncanakan dan direalisasikan untuk pencapaian tujuan administrasi pendidikan.

8. Penilaian (Evaluating)

Kegiatan evaluasi ini bertujuan untuk meneliti dan mengetahui efektivitas pelaksanaan proses keseluruhan organisasi dalam upaya pencapaian hasil sesuai program yang ditetapkan dalam kaitannya untuk pencapaian tujuan pendidikan.

\section{H. Ruang Lingkup Administrasi Pendidikan}

Ini merupakan hal-hal yang dapat membantu penyelenggaraan berbagai kegiatan pendidikan sehingga tujuan pendidikan dapat tercapai dengan baik. Mengacu pada pengertiannya di atas, berikut ini adalah beberapa bidang penting yang termasuk di dalam ruang lingkup administrasi pendidikan:

1. Bidang Tata Usaha Sekolah

- Organisasi dan struktur pegawai tata usaha

- Anggaran belanja keuangan sekolah

- Masalah kepegawaian dan personalia sekolah

- Keuangan dan pembukuan

- Korespondensi/ surat menyurat

- Masalah pengangkatan, pemindahan, penempatan, laporan, pengisian buku induk, raport, dan sebagainya

\section{Bidang Personalia Murid}

- Organisasi murid

- Masalah kesehatan murid

- Evaluasi kemajuan murid 
- Masalah kesejahteraan murid

- Bimbingan dan konseling untuk murid

3. Bidang Personalia Guru

- Pengangkatan dan penempatan guru

- Organisasi person guru

- Masalah kepegawaian

- Masalah kondisi dan evaluasi kemajuan guru

- Refreshing dan upgrading guru

4. Bidang Pengawasan (Supervisi)

- Upaya meningkatkan semangat guru dan pegawai tata usaha.

- Mengupayakan dan mengembangkan kerjasama yang baik antara guru, murid, dan pegawai tata usaha sekolah.

- Mengupayakan dan membuat pedoman cara-cara menilai hasil-hasil pendidikan dan pengajaran.

- Upaya untuk meningkatkan mutu dan pengalaman guru.

5. Bidang Pelaksanaan dan Pembinaan Kurikulum

- Berpedoman dan menerapkan kurikulum sekolah, dalam upaya mencapai dasardasar dan tujuan pendidikan dan pengajaran.

- Melaksanakan organisasi kurikulum beserta metode-metodenya, sesuai dengan pembaharuan pendidikan dan lingkungan masyarakat. 


\section{DAFTAR PUSTAKA}

Al-Maturi, Abu Mansur. 2012. Dasar-dasar Administrasi Pendidikan, dalam http://edimansure.blogspot.co.id/2012/10/dasar-dasar-administrasi- pendidikan.html, diunggah pada Senin, 22 Oktober 2012 pukul 07.02 WIB

Arsyam, M. (2020). Manajemen pendidikan islam.

Arsyam, M., \& Alwi, A. M. (2020). MANAJEMEN HIDUP DALAM PERSPEKTIF AL-QUR'AN.

Arsyam, M., \& Kusnadi Umar, Z. Z. MANUSIA SEBAGAI PENDIDIK PERPEKTIF ISLAM DAN BARAT.

Asmani, Jamal Ma'mur. 2011.Tips Praktis Membangun dan Mengolah Administrasi Sekolah.Jogja:Diva Press.

Daryanto, Drs. H.M.2001. Administrasi Pendidikan.Jakarta: Rekaka Cipta.

Hamalik, Oemar.2006. Manajemen Pengembangan Kurikulum,Bandung: PT Remaja Rosdakarya.

Makmur, Z., Arsyam, M., \& Alwi, A. M. S. (2020). Strategi Komunikasi Pembelajaran Di Rumah Dalam Lingkungan Keluarga Masa Pandemi. KOMUNIDA: Media Komunikasi dan Dakwah, 10(02), 231-241.

Ngalim Purwanto (1993), Administrasi dan Supervisi pendidikan, Rodakarya, Bandung Jawa barat.

Nawawi, DR. Hadari. 1997, Administrasi Pendidikan,Jakarta: Gunung Agung.

Nahiyah, Sopiatun.2012, Makalah Administrasi Pendidikan, dalam http://sopiatunnahwiyah.blogspot.com/2012/10/makalah-administrasi- pendidikan.html. diunggah pada Jum'at, 18 september 2015 Pukul 22.09 WIB

Prihatin Eka. 2011. Teori Administrasi Pendidikan, Bandung; Alfabeta

Zakirah, Z., Jumliadi, J., Arsyam, M., Herianto, H., Rusli, M., \& Alwi, A. M. Implementation of The Islamic Local Regulations in Bulukumba Regency. 